\title{
V ENEI
}

\section{Investimentos em Pesquisa, Desenvolvimento e Demonstração em Energia no Brasil: processo de mensuração e primeiros resultados.}

\author{
Silvia Angelica D. de Carvalho (FCA/UNESP); \\ Andre Tosi Furtado (IG/UNICAMP); \\ Barbara Bressan (CGEE); \\ Luccas Motta (CGEE);
}

\begin{abstract}
resumo:
O artigo tem como objetivo apresentar o processo de mensuração dos investimentos em pesquisa, desenvolvimento e demonstração (PD\&D) em energia no Brasil, assim como as primeiras estimativas sobre esses montantes. Essas dados são relevantes para a melhor compreensão do destino final dos recursos destinados à PD\&D, fornecendo subsídios para a formulação e o aprimoramento de políticas públicas sistemáticas para impulsionar o setor de energia e promover a transição energética no país. A mensuração dos investimentos em PD\&D, classificando-os por categoria energética em nível de 2 dígitos, de acordo com a proposta da Agência Internacional de Energia (IEA), permitiu ao Brasil integrar o banco de dados da agência e, e partir disso, possibilitará análises comparativas destes dados com países da OECD. O escopo das informações foi restrito a fontes de dados secundários de órgãos públicos e o período de referência foi 2013 a 2018. As primeiras estimativas permitiram identificar a queda na participação dos investimentos em energias renováveis no total de investimentos em PD\&D. A evolução dos investimentos públicos brasileiros em PD\&D em energias renováveis, entre 2013 e 2018, aponta como principais fontes os biocombustíveis e a energia solar. Com relação à participação dos órgãos e programas federais, há forte presença do BNDES e da ANEEL enquanto que FINEP e Petrobras reduziram expressivamente seus investimentos de PD\&D em energia.
\end{abstract}

palavras-chave: energias renováveis; dispêndio federal; política energética; planejamento energético;

Código JEL: O32

Área Temática: Indicadores de Ciência, Tecnologia e Inovação 


\section{Introdução}

O trabalho de pesquisa, que foi base para este artigo, buscou desenvolver um processo de mensuração dos investimentos em pesquisa, desenvolvimento e demonstração (PD\&D) em energias sustentáveis (ES) no Brasil e representa uma iniciativa pioneira de sistematização de informações sobre as fontes dos recursos, os principais atores responsáveis pelo seu financiamento e/ou execução e da classificação dos projetos em áreas tecnológicas. A intenção dessa pesquisa foi melhorar a compreensão sobre o destino final dos esforços em PD\&D no setor energético e, assim, oferecer subsídios para a formulação e o aprimoramento de políticas públicas sistemáticas para impulsionar o setor de energias sustentáveis no Brasil ${ }^{1}$.

A importância do estudo centra-se na necessidade de diversificação da matriz energética brasileira com vistas a cumprir as metas acordadas pelo Brasil no Acordo de Paris.

$\mathrm{O}$ escopo do trabalho foi restrito às fontes de dados secundários de órgãos públicos, onde o acesso à informação torna-se facilitado devido à Lei de Acesso à Informação e consequente disponibilização dos dados. A caracterização das fontes de dados permitiu identificar a origem dos fluxos de investimento em PD\&D, mas não as entidades executoras. Se bem esses dados são controlados e fiscalizados por órgãos públicos, nem todos são financiados por estes órgãos. Neste sentido, o critério adotado para o levantamento de dados permite identificar investimentos que podem ser caracterizados de acordo com a metodologia do Manual Frascati (OECD, 2015) como sendo financiados e/ou executados por empresas públicas ou privadas.

Além do esforço de levantamento dos investimentos em PD\&D, este trabalho propõe a classificação desses investimentos por categoria energética, em nível de 2 dígitos propostos pela IEA (Agência Internacional de Energia). Essa agência encarrega-se de centralizar as estatísticas de PD\&D em energia dos países da OCDE e representa uma referência para essas estatísticas em todo o mundo. Com esses dados, torna-se possível realizar o benchmarking dos investimentos em PD\&D em energia do Brasil com outros países do mundo e, além disso, permitiram iniciar uma ampla discussão sobre a sistematização das informações e construção de indicadores para o setor de energia no país.

Desta forma, o artigo apresenta brevemente o referencial teórico e os conceitos importantes, descreve os principais aspectos da construção da metodologia de mensuração dos investimentos em PD\&D em energia e traz as primeiras estimativas para o país.

\section{Mensuração dos dados de PD\&D em energia no Brasil: referências e método.}

A mensuração dos dispêndios de P\&D pautam-se nas orientações do Manual Frascati (OCDE, 2002), que desagrega os indicadores de P\&D em três dimensões:

- Natureza: pesquisa básica, pesquisa aplicada e desenvolvimento experimental;

- Os setores que executam e financiam as atividades de P\&D: governo, instituições de ensino superior, empresas e organizações sem fins lucrativos e exterior;

- A orientação dos recursos de cada um desses setores, obedecendo a critérios específicos para o governo (segundo objetivos socioeconômicos), para as instituições de ensino superior (segundo áreas do conhecimento) e para as empresas (segundo setores de atividade econômica).

Hollanda (2003) salienta que, na análise dos dados de P\&D, deve-se considerar:

i. Que as séries são apenas o reflexo quantitativo sumário de padrões muito complexos de atividades e instituições (...) o tamanho, as aspirações, a estrutura econômica e os arranjos institucionais dos países envolvidos devem ser levados em consideração (OCDE, 2002);

\footnotetext{
${ }^{1}$ O projeto Energy Big Push (ou Grande Impulso Energia) é coordenado pela Comissão Econômica para a América Latina e Caribe (CEPAL) e é executado no Brasil em parceria com o Centro de Gestão e Estudos Estratégicos (CGEE), contando com contribuições de diversos órgãos ligados aos temas de energia e inovação, que são: Empresa de Pesquisa Energética (EPE), Ministério de Minas e Energia (MME), Ministério de Relações Exteriores (MRE), Ministério da Ciência, Tecnologia, Inovação e Comunicações (MCTIC), Agência Nacional de Energia Elétrica (Aneel), Financiadora de Estudos e Projetos (Finep), Empresa Brasileira de Pesquisa e Inovação Industrial (Embrapii), Banco Nacional de Desenvolvimento Econômico e Social (BNDES), Instituto de Pesquisa de Econômica Aplicada (Ipea) e Agência Internacional de Energia (IEA, na sigla em inglês). Mais informações em: https://www.cepal.org/pt-br/proyectos/energy-big-push-grande-impulso-energia-brasil.
} 
ii. Dificuldades quanto à qualidade e a comparabilidade dos dados estatísticos no país envolvem a mensuração de todo tipo de dado, não somente os de P\&D. Assim, especificar de maneira clara os "desvios" possíveis relacionados a cada banco de dados é importante, tais como: a) quebra nas séries; b) áreas de conhecimento cobertas pelos dados; c) determinação do montante de recursos dedicados à $\mathrm{P} \& \mathrm{D}$ no setor de ensino superior, dada a estreita relação entre o ensino e a pesquisa; d) diferenças na cobertura dos setores de ensino superior e de governo, devido à existência de instituições na "fronteira" de ambos; e) a inclusão ou não dos institutos de P\&D a serviço de empresas e a sua classificação setorial (OCDE, 2002);

iii. A análise dos indicadores brasileiros de P\&D estão consideravelmente "colados" aos dispêndios das chamadas instituições típicas de P\&D. Isso faz com que os dados mais agregados possam ser considerados relativamente mais confiáveis do que os valores desagregados, deduzidos a partir de interpretações complexas da execução orçamentária;

iv. Não se deve perder de vista a necessidade de garantir a padronização e a comparabilidade dos dados produzidos no país, assim como a transparência metodológica na apresentação das séries produzidas;

Hollanda (2003) ressalta que a mensuração dos recursos aplicados pelo governo, realizados a partir do orçamento, deve ser feita a partir da identificação das rubricas orçamentárias relativas a P\&D e contabilizados - ou estimados - os valores correspondentes. As vantagens de se considerar o orçamento e não o valor executado envolvem, primeiro, a menor complexidade na atualização das séries de dados e, segundo, que os objetivos socioeconômicos dos dispêndios são derivados mais precisamente do orçamento, refletindo decisões relativas à alocação de recursos. Portanto, representam vantagens significativas do ponto de vista da formulação e avaliação das políticas voltadas à P\&D.

Santos (2015), por meio do IPEA, realizou um estudo sobre os recursos de P\&D aplicados em energias renováveis e identificou que os desafios para o Brasil no apoio à $\mathrm{P} \& \mathrm{D}$ na produção de Energias renováveis envolvem: i. a promoção de soluções tecnológicas com viabilidade econômica, ambiental e social para Energias renováveis; ii. o estímulo às capacidades industriais e tecnológicas locais para além da geração de energia e a conquista de parcela do mercado de projetos, insumos e bens de capital de alta tecnologia na área. Nesse aspecto, entendemos a importância de mapear os esforços tecnológicos nacionais para que a transição energética se apoie em capacidades tecnológicas locais. Ou seja, mensurar qual o potencial nacional de $\mathrm{P} \& \mathrm{D}$ para desenvolver internamente toda a cadeia produtiva na área de Energias renováveis e se tornar exportador de conhecimentos e equipamentos relacionados a essas tecnologias.

Santos (2015) aponta que, no plano global, a aposta em Energias renováveis, apoiada pela P\&D pública e privada, tem contribuído para a redução de custos totais, tornando essas fontes viáveis em quase todas as suas modalidades de primeira geração (exceto em situações de subsídios de outras fontes) e a participação do Estado tem sido imprescindível para o crescimento da oferta de energias e também para o financiamento da pesquisa no setor. O grau esperado de dependência dos recursos públicos tende a ser descendente ao longo do tempo, o que tem sido observado em países como Alemanha, França, Estados Unidos e Japão, desde os anos 1980.

Segundo Santos (2015), verifica-se, nesses países, redução da participação de recursos públicos diante de maiores aportes do setor privado na medida em que a atividade produtiva viabiliza a P\&D. Ou seja, os investimentos privados cresceram proporcionalmente mais após um período de intensa orientação da P\&D a partir de aportes do setor público. Vale ressaltar que o volume de recursos investidos em Energias renováveis pelo setor público não diminuiu, o que mudou foi a sua participação no total investido em Energias renováveis. As trajetórias sinalizam que o setor privado incorpora uma parcela maior dos custos com $\mathrm{P} \& \mathrm{D}$ em Energias renováveis, reduzindo a participação estatal direta (os aportes totais aumentam), uma resposta natural do mercado em desenvolvimento. Desde os anos 2000, nota-se estabilização nestas taxas de participação dos dois setores (público e privado) e até um leve aumento do estatal, o que pode indicar efeito do aumento da P\&D total, diante da oscilação e de aumentos mais acentuados nos preços internacionais da energia de fontes concorrentes, não renováveis, ou o efeito das crises econômicas.

E no Brasil? Uma comparação dos gastos totais em Energias renováveis, segundo Santos (2015), não foi possível devido à indisponibilidade de dados sistematizados, justamente o que esta pesquisa se propôs a construir, de forma progressiva, iniciando pela organização e mapeamento dos gastos geridos por órgãos públicos e, futuramente, dos gastos privados e dos governos estaduais.

Segundo Santos (2015) fato importante no desenvolvimento do setor de energia no Brasil é a separação completa entre a estrutura de regulação e promoção da produção de energia, a cargo do Ministério de Minas e Energia (MME) e a correspondente estrutura de pesquisa, a cargo do MCTI. A estrutura de gestão do apoio à $\mathrm{P} \& \mathrm{D}$ em Energias renováveis, no âmbito do governo federal, tem forte 
concentração na Casa Civil e em Conselhos Ministeriais (de energia e do biodiesel, por exemplo), há ausência de políticas sólidas, de revisão periódica pelo Parlamento, como têm sido feito em outros países.

Assim, para entender a amplitude da transição energética brasileira, será importante acompanhar a evolução da relação dos investimentos públicos e privados em $\mathrm{P} \& \mathrm{D}$, observando se há indícios de desenvolvimento, organização e crescimento do setor privado nas áreas energéticas e, portanto, que os investimentos públicos e os mecanismos implementados geraram o desenvolvimento econômico esperado e promoveram a estruturação da cadeia produtiva de energias renováveis no país.

A projeção de crescimento do consumo energético no país, previsto em 2,3\% a.a. de 2017 a 2027 (EPE, 2018), tendo em vista o aumento do consumo per capita de 1,7\% a.a., e as metas da NCD estabelecidas pelo Governo brasileiro na Conferência de Paris (BRASIL, 2016) são as principais motivações ao financiamento da P\&D em energias sustentáveis, apesar da menor dependência brasileira de fontes fósseis perto das matrizes de grande maioria dos países desenvolvidos.

O desafio é mensurar quais tipos de tecnologias estão sendo desenvolvidas e se estas tecnologias atendem às diversas etapas da cadeia energética das distintas fontes de renováveis e de eficiência energética, e se não, quais são as linhas de $P \& D$ que deveriam ser incentivadas para promover tal desenvolvimento e não ampliar a dependência de importação de tecnologia do país, pelo contrário, identificar as oportunidades para a exportação de tecnologias em energias sustentáveis.

\subsection{Definições importantes e escopo da pesquisa}

O primeiro termo importante a ser definido relaciona-se ao que se considera como energias sustentáveis. O termo energias sustentáveis se apoia na definição da ODS 7 que contempla as tecnologias relacionadas às energias renováveis e à eficiência energética. É importante salientar que a mencionada ODS coloca no item 7.1 a meta de inclusão social através do acesso universal e a custos acessíveis dos serviços energéticos.

A International Energy Agency (IEA, 2011), uma das principais referências dessa pesquisa, usa a definição tecnologias de baixo carbono (low carbon technologies) que é mais ampla. Esse termo engloba as fontes de energia e tecnologias de transformação de baixo impacto na emissão de gases de efeito estufa, principalmente o gás carbônico. Nessa categoria se incluem sete grandes grupos de tecnologias: a fissão e fusão nuclear e as tecnologias de captura e sequestro de carbono, além das energias renováveis, da eficiência energética, o hidrogênio e células combustíveis, outras tecnologias de geração elétrica, transmissão e armazenamento, e de tecnologias transversais. Entretanto, essa classificação não se adequa com o conceito de sustentabilidade por incluir as fontes de energia não renováveis ou com emissões nocivas ao meio ambiente como a nuclear, pela sua geração de radiação e de resíduos radioativos, e as tecnologias de captura e sequestro de carbono, porque apenas buscam mitigar impactos negativos de energias fósseis poluentes e não renováveis. Dentro da classificação de tecnologias energéticas apresentadas pela IEA, incluímos os seguintes grupos: Grupo 1: Eficiência Energética; Grupo 3: Fontes Renováveis de Energia; Grupo 5: Hidrogênio e Células Combustíveis; Grupo 6: Outras Tecnologias de Geração e Armazenamento de Energia Elétrica; Grupo 7: Outras Pesquisas e Tecnologias de Fronteira (Quadro 1).

$\mathrm{O}$ segundo termo importante corresponde à conceituação de pesquisa, desenvolvimento e demonstração (PD\&D). A IEA (2011), embora paute-se na terminologia adotada pelo Manual Frascati para a definição da $P \& D$ em energia, amplia o seu indicador ao incluir as informações sobre demonstração.

O Manual Frascati (OECD, 2015) conceitua P\&D como o trabalho criativo realizado de forma sistemática, a fim de aumentar o estoque de conhecimento, incluindo o conhecimento do homem, da cultura e da sociedade, e o uso desse estoque de conhecimento para criar novas aplicações. Neste Manual, a P\&D abrange três atividades:

- Pesquisa básica: o trabalho experimental ou teórico realizado principalmente para adquirir novos conhecimentos sobre a base subjacente de fenômenos e fatos observáveis, sem qualquer particular aplicação ou uso em vista.

- Pesquisa aplicada: a investigação original realizada com o objetivo de adquirir novos conhecimentos. É, no entanto, dirigida principalmente para um objetivo ou objetivo específico.

- Desenvolvimento experimental: o trabalho sistemático, com base no conhecimento existente obtido a partir de pesquisa e / ou experiência prática, que é direcionado para a produção de novos materiais, produtos ou dispositivos, para instalar novos processos, sistemas e serviços, ou para melhorar substancialmente aqueles já produzidos ou instalados. 
manual da IEA (IEA, 2011), inclui pesquisa, desenvolvimento e demonstração, quando o trabalho se aplica a tecnologias que são usadas para extrair, converter, gerar, transportar, distribuir, controlar e usar energia. Nesse contexto, a energia deve incluir toda a cadeia, desde as formas primárias encontradas na natureza, passando pelas formas secundárias mais convenientes para o transporte e o armazenamento, até os usos finais, como calor, luz, força motriz e outros serviços de energia.

O conceito de P\&D de Energia da IEA difere do conceito de P\&D do Manual Frascati, pois: (i) se concentra apenas em programas públicos relacionados à energia; (ii) inclui "projetos de demonstração"; e (iii) inclui empresas estatais. A IEA decidiu incluir projetos de demonstração, porque muitas vezes essa é uma parte importante do desenvolvimento de novas tecnologias, dado que o resultado do projeto pode ser incerto e há um elemento de risco que muitas vezes é grande demais para o setor privado assumir sozinho.

Assim, a PD\&D em energia abrange pesquisa, desenvolvimento e demonstração relacionados à produção, armazenamento, transporte, distribuição e uso racional de todas as formas de energia. Para fins de PD\&D de energia, as empresas estatais devem ser consideradas entidades públicas, mas apresentadas separadamente. (IEA, 2011).

Na metodologia da IEA (IEA, 2011), em primeiro lugar, é importante distinguir que as estimativas de PD\&D podem ser relatadas: (i) do ponto de vista do executor como despesas; ou (ii) de uma perspectiva de financiador como orçamentos. Os gastos intrínsecos de PD\&D podem ser calculados com base em pesquisas das unidades que realizam PD\&D, a fim de identificar o valor efetivamente gasto em PD\&D. As fontes dos dados são os executores, ou seja, as entidades que desenvolvem a atividade de PD\&D em todos os setores, tanto no setor público quanto no privado. $O$ análogo a este conceito no Manual Frascati para $\mathrm{P} \& \mathrm{D}$ é o dispêndio bruto em $\mathrm{P} \& \mathrm{D}$ (GERD), portanto, a soma dos gastos em $\mathrm{P} \& \mathrm{D}$ em um território nacional poderia ser conhecida como "dispêndio interno bruto em P\&D", parte da qual é financiada pelo governo. Essas informações também podem ser coletadas dos executores, como no caso da DRGE. (IEA, 2011)

Infelizmente, mesmo com fontes estatísticas em vigor, uma medida de dados GERD financiados pelo governo não se tornaria disponível até entre um e dois anos após a realização da PD\&D. Além disso, as unidades que executam a PD\&D que respondem às pesquisas, às vezes não conseguem relatar onde sua concessão ou contrato específico se enquadra na política geral de energia do governo. Uma maneira alternativa de medir o apoio do governo a PD\&D foi desenvolvida pela IEA usando dados de orçamentos e fontes administrativas relacionadas. (IEA, 2011)

Os orçamentos de PD\&D são calculados identificando todos os itens do orçamento que envolvem PD\&D e medindo ou estimando seu conteúdo de PD\&D em termos de financiamento. Essas estimativas podem ser menos precisas do que dados baseados no desempenho, mas como são derivados do orçamento, eles podem ser vinculados à política por meio da classificação por "objetivos" ou "metas". No contexto do Manual Frascati sobre P\&D, os dados baseados no orçamento são chamados de "dotações orçamentárias do governo ou gastos com PD\&D”. (GBAORD). (IEA, 2011)

Os valores orçamentários são frequentemente apropriados por períodos mais longos do que um ano. Eles também podem ser revisados de ano para ano com base em novas alocações orçamentárias. Os orçamentos estimados e as despesas reais dos governos geralmente diferem porque os valores projetados de PD\&D no estágio de apropriações são diferentes do que é medido pelos executores. Também pode ser devido a uma imprecisão nas dotações orçamentárias que não permite a identificação separada de dotações que são especificamente direcionadas para PD\&D. (IEA, 2011)

Os orçamentos de PD\&D em energia recolhidos pela IEA devem ser reportados com base no GBAORD, com base nas informações fornecidas pelos financiadores. Os dados da IEA relacionam os recursos em PD\&D a partir das fontes de financiamento GBARD (alocações orçamentárias do governo para $\mathrm{P} \& \mathrm{D}$ ) ou a GOVERDs (gastos governamentais com P\&D). A metodologia de mensuração da IEA pautou a coleta de dados deste trabalho embora, no Brasil, seja muito difícil separar os recursos do financiamento dos dados de execução. Assim, o esforço será no sentido de reunir os dados das fontes de financiamento (GBARD), excluindo o financiamento para organizações localizadas no exterior.

A metodologia da IEA (IEA, 2011) inclui, no orçamento público de PD\&D, unidades do governo federal e unidades do governo estadual, assim como os investimentos em PD\&D das empresas estatais. No âmbito deste projeto, somente o orçamento público de PD\&D do governo federal e empresas estatais foram considerados. Os dados de dispêndio públicos estaduais em P\&D se apoiam em estatísticas produzidas pelas Secretarias de Ciência e Tecnologia ou entidades afins dos estados brasileiros. Contudo, neste momento, foi proposto, com base na mesma metodologia de classificação adotadas para órgãos 
federais, uma primeira experiência de mensuração com o Estado de São Paulo², isso porque é um grande desafio coletar esses dados de forma desagregada por grupos ou tecnologias de energia. O mesmo desafio existe para os investimentos privados em PD\&D na área de energias sustentáveis.

Os dados nacionais de dispêndio anual de $\mathrm{P} \& \mathrm{D}$, atualmente levantados pelo MCTI junto ao setor público $^{3}$ e privado ${ }^{4}$, não contemplam a informação sobre as tecnologias em que são aplicados, assim, devido às limitações das fontes de informação e das bases de dados existentes, foi adotada uma estratégia progressiva de obtenção desses dados, inicialmente centrada nas organizações públicas e privilegiando as fontes de financiamento por meio de dados orçamentários e extra-orçamentários de entidades públicas, incluindo-se entre elas as empresas estatais.

Nas estatísticas tradicionais de $\mathrm{P} \& \mathrm{D}$, as empresas públicas não são consideradas estabelecimentos governamentais, pois são tratados como parte do setor empresarial. No entanto, segundo a IEA (2011), para os objetivos de pesquisa e desenvolvimento relacionados à energia, as empresas estatais devem ser tratadas como órgãos públicos. A PD\&D dessas empresas é bastante grande para determinados setores. Em muitos, mas não em todos os casos, parte do financiamento vem do dinheiro dos impostos públicos. Se os gastos em PD\&D dessas empresas fossem excluídos, a utilidade dos orçamentos de energia em PD\&D diminuiria consideravelmente. Contudo, deve-se tomar cuidado para evitar a dupla contagem de qualquer PD\&D que já possa figurar nos orçamentos governamentais de P\&D.

As categorias de energias da metodologia da IEA (IEA, 2011) definem os grupos de categorias de PD\&D relacionados à energia conforme o quadro 1. Nesta pesquisa, os dados serão identificados ao nível de 1 dígitos e nos níveis de 2 e 3 dígitos, quando possível. No Brasil, há uma tradição fraca de dados de P\&D por objetivo socioeconômico, que está disponível apenas para o setor público. A classificação por objetivo socioeconômico é muito agregada, incluindo apenas energia, mas grande parte do gasto público é incluído no ensino superior. Este trabalho utilizou a classificação de categorias de energia da IEA e incluiu combustíveis fósseis e nucleares para permitir a comparação com os dados de PD\&D de países desenvolvidos e em desenvolvimento no banco de dados da IEA.

\begin{tabular}{|c|c|}
\hline \multicolumn{2}{|c|}{ Quadro 1 - Categorias de Energia } \\
\hline Classificação dos grupos de energia & Classificação das categorias de energia \\
\hline 1. Eficiência energética & $\begin{array}{l}\text { 1.1 Tecnologias de eficiência energética aplicadas à indústria } \\
\text { 1.2 Tecnologias de eficiência energética aplicada a residências e estabelecimentos } \\
\text { comerciais } \\
\text { 1.3 Tecnologias de eficiência energética aplicadas ao setor de transporte rodoviário } \\
\text { 1.4 Outras tecnologias de eficiência energética } \\
\text { 1.9 Eficiência energética não alocado }\end{array}$ \\
\hline 2. Energias fósseis: petróleo, gás natural e carvão mineral & $\begin{array}{l}\text { 2.1 Petróleo e gás natural } \\
\text { 2.2 Carvão mineral } \\
\text { 2.3 Separação, captura, transporte e armazenamento de dióxido de carbono (CO2) } \\
\text { 2.9 Outras tecnologias fósseis não alocadas }\end{array}$ \\
\hline 3. Fontes de energia renováveis & $\begin{array}{l}\text { 3.1 Energia solar } \\
\text { 3.2 Energia eólica } \\
\text { 3.3 Energia dos oceanos } \\
\text { 3.4 Biocombustíveis } \\
\text { 3.5 Energia geotérmica } \\
\text { 3.6 Hidroeletricidade } \\
\text { 3.7 Outras energias renováveis } \\
\text { 3.9 Outras renováveis não alocadas }\end{array}$ \\
\hline 4. Fissão e fusão nuclear & $\begin{array}{l}\text { 4.1 Fissão nuclear } \\
\text { 4.2 Fusão nuclear } \\
\text { 4.9 Outros fusão e fissão não alocados }\end{array}$ \\
\hline 5. Hidrogênio e células a combustível & $\begin{array}{l}\text { 5.1 Hidrogênio } \\
\text { 5.2 Células a combustível } \\
\text { 5.9 Outras hidrogênio e células a combustível não alocados }\end{array}$ \\
\hline 6. Outras tecnologias elétricas e de armazenamento & $\begin{array}{l}\text { 6.1 Outras tecnologias de geração } \\
6.2 \text { Transmissão, distribuição } \\
6.3 \text { Armazenamento de energia } \\
6.9 \text { Outros geração e armazenamento não alocados }\end{array}$ \\
\hline 7. Outras tecnologias transversais & $\begin{array}{l}\text { 7.1 Análise de sistemas energéticos } \\
\text { 7.2 Pesquisa básica sobre energia } \\
\text { 7.3 Outras }\end{array}$ \\
\hline
\end{tabular}

Fonte: IEA, 2011.

${ }^{2}$ O Estado de São Paulo representava 59,1\% do dispêndio estadual em P\&D em 2011, segundo dados da Fapesp (FAPESP, 2014). Além de possuir programas reconhecidamente importantes na área de energia como o BIOEN/FAPESP e na atuação das três universidades estaduais (USP, UNICAMP e UNESP) na área.

${ }^{3}$ Os dados do MCTIC de dispêndio público de P\&D por objetivo socioeconômico contemplam a rubrica de energia, que em 2013 foram de 157,8 milhões de reais (MCTIC, 2019). Contudo essa cifra é certamente subestimada porque os demais objetivos socioeconômicos, principalmente ensino superior, englobam atividades de P\&D relacionadas com energia. Ademais, essa série de dados se encontra interrompida em 2013.

${ }^{4}$ Os dados de dispêndio de P\&D do setor produtivo industrial e terciário são levantados pelo IBGE em pesquisas que são realizadas a cada 3 anos, a PINTEC. Esses dados, embora bastante detalhados, não contém indicação da área tecnológica para a qual se destinam. 


\subsection{Aspectos metodológicos que delimitaram as bases de dados analisadas}

O esforço inicial de organização desses dados contou com as bases que reúnem o maior volume de financiamentos e o maior número de projetos, construindo uma estimativa e ajustando a metodologia de coleta e organização das informações para, num segundo momento, buscar os dados que estão menos sistematizados e organizados.

Com base no problema considerado, que envolve a mensuração da PD\&D para o setor energético em energias sustentáveis no Brasil, foram delimitadas as seguintes perguntas norteadoras da metodologia de busca das informações nas bases de dados:

- Quais são os dispêndios brasileiros em PD\&D em energia?

- Qual é a importância dos dispêndios em PD\&D em energias sustentáveis?

- Quais são as fontes de energias sustentáveis mais apoiadas pelo setor público brasileiro?

- Quais são os principais órgãos e programas federais que financiam a PD\&D em energias sustentáveis?

Alguns elementos da metodologia para identificar, nas bases de dados existentes, a parcela destinada à PD\&D na área de energia, subdividida por tecnologia energética, foram adaptados do estudo do IPEA sobre os fundos setoriais (SANTOS, 2015). Os passos realizados são apresentados abaixo:

i. Utilização de termos de busca ${ }^{5}$ para a identificação e classificação das categorias e tecnologias em energias, a partir da base completa dos projetos aprovados; utilizando-se os campos "título", "objetivo", "palavras-chave", "descrição", "linha de pesquisa" e "área de pesquisa". Os termos relacionados foram buscados isoladamente e combinados entre si para identificação dos dispêndios por cada categoria, processo que demandou auxilio especializado em tecnologia da informação e mineração de dados da equipe do CGEE;

ii. Agrupamento e classificação dos projetos selecionados na etapa anterior, classificando-os de acordo com o tipo de tecnologia energética, de acordo com as categorias delimitadas na metodologia da IEA, conforme os termos de busca associados;

iii. Analise qualitativa do perfil, destacando os valores, total por ano, tipo de fonte, atores, etc.

O primeiro ponto observado foi o período de abrangência dos dados coletados. Foi estabelecido o período dos 5 anos anteriores ao início da pesquisa que foi 2019, portanto, os dados se referem ao período de 2013 a 2018. Além da busca por coletar os dados mais recentes que estivessem disponíveis, considerouse também que os projetos de PD\&D, em geral, envolvessem um horizonte de 2 a 4 anos de duração, e assim os dados conseguiriam absorver um conjunto maior de projetos completos financiados. Outro ponto importante observado, foi a comparabilidade internacional dos dados brasileiros com informações similares de outros país.

Os dados provenientes dos bancos de dados estão organizados por projeto de pesquisa, que é o indivíduo estatístico ao qual estão relacionadas as demais informações destes bancos de dados. Para a mensuração e categorização dos projetos foram aplicados termos de busca ao título, resumo, palavraschave e qualquer outra descrição mais detalhada do mesmo, o que permitiu atribuir ao projeto em questão uma determinada tecnologia energética. As informações sobre os projetos continham informações sobre o montante de recursos alocados e sua distribuição temporal. Convém assinalar que o Manual do IEA aconselha ratear o montante de recursos pelos períodos anuais de execução, e assim foi feito.

\subsection{Os Fluxos e a Natureza dos Investimentos de PD\&D no setor de energia no Brasil}

Os dados sobre os investimentos públicos e publicamente orientados de PD\&D em tecnologias energéticas têm natureza e origem distintas. Alguns derivam de dotações orçamentárias do Governo Federal enquanto outros derivam de legislações e regulamentações que orientam a ação de empresas pertencentes ao setor energético obrigando-as a realizar investimentos em PD\&D. Há o caso ainda de agentes financeiros federais que realizam empréstimos direcionados para inovação em empresas. Neste trabalho, entende-se que os empréstimos realizados por Instituições Financeiras Públicas e os

\footnotetext{
${ }^{5}$ A lista completa dos termos de busca utilizados está disponível no relatório de pesquisa na página da CEPAL: https://www.cepal.org/pt-br/proyectos/energy-big-push-grande-impulso-energia-brasil.
} 
investimentos em PD\&D efetuados por empresas em decorrência de obrigação legal, podem ser considerados como recursos em PD\&D orientados por políticas públicas, ou seja, publicamente orientados. A principal razão consiste em que o investimento privado provavelmente não ocorreria sem a indução da política pública, que pode ser compulsória, no caso da cláusula de $\mathrm{P} \& \mathrm{D}$, ou realizada por um instrumento de financiamento mais vantajoso que o mercado, como é o caso dos empréstimos do BNDES e da Finep. Tanto neste caso quanto no caso da cláusula de $\mathrm{P} \& \mathrm{D}$ são recursos que se enquadram dentro de programas públicos cuja finalidade é induzir as empresas a efetuarem investimentos em PD\&D em áreas consideradas prioritárias ou estratégicas pelo Governo.

O Manual Frascati (OECD, 2015) trabalha com dois tipos de dados: os investimentos executados e os financiamentos, sendo que esses dados podem ter origem numa mesma entidade ou em entidades distintas. O Manual Frascati também distingue nos fluxos de financiamento aqueles que constituem transferências unilaterais, como as que ocorrem entre uma agência de fomento e uma instituição de pesquisa, e a compra de $\mathrm{P} \& \mathrm{D}$ de uma empresa por uma instituição pública de pesquisa. Cabe também salientar que este Manual considera empréstimos, participações acionárias, realizados por agentes financeiros públicos em empresas como sendo investimentos em P\&D financiados pelas mesmas.

O Quadro 2 apresenta as principais fontes de dados consideradas neste trabalho e descreve como elas se enquadram nos conceitos de fluxos monetários de P\&D, apresentados pelo Manual Frascati, e de financiamento de empresas orientado por políticas públicas. A primeira coluna exibe a origem do recurso, que pode ser o orçamento federal, como no caso do FNDCT e demais verbas orçamentárias, ou apoiado em empréstimos, como é o caso da Finep ou do BNDES, ou então ter origem na própria empresa. Neste último caso, temos as despesas obrigatórias das empresas do setor de energia, regulamentadas pelas agências reguladoras, mas também investimentos das empresas estatais.

Quadro 2: Fluxos de Investimento em PD\&D e sua Classificação segundo o Manual Frascati

\begin{tabular}{|c|c|c|c|c|}
\hline Origem do Recurso & Órgão Público & Executores da PD\&D & Natureza do Fluxo & Forma de Contabilização \\
\hline FNDCT & \multirow[b]{2}{*}{ FINEP } & ICT & Transferência & Financiamento Público \\
\hline FINEP & & Empresa & Empréstimo & $\begin{array}{l}\text { Financiamento da Empresa } \\
\text { Orientado por Política Pública }\end{array}$ \\
\hline FNDCT & \multirow{2}{*}{$\mathrm{CNPq}$} & \multirow{2}{*}{ ICT } & \multirow{2}{*}{ Transferência } & \multirow{2}{*}{ Financiamento Público } \\
\hline Outros Orçamento & & & & \\
\hline Orçamento Federal & MCTI & CNEN & Execução Interna & Financiamento Público \\
\hline \multirow[b]{2}{*}{ Empresa } & \multirow[b]{2}{*}{ Aneel } & Própria Empresa & Execução interna & \multirow{2}{*}{$\begin{array}{l}\text { Financiamento da Empresa } \\
\text { Orientado por Política Pública }\end{array}$} \\
\hline & & $\begin{array}{c}\text { ICT } \\
\text { Outra Empresa }\end{array}$ & Compra de PD\&D & \\
\hline \multirow{2}{*}{ Empresa } & \multirow{2}{*}{ ANP } & Própria Empresa & $\begin{array}{l}\text { Execução interna com } \\
\text { recursos internos }\end{array}$ & \multirow{2}{*}{$\begin{array}{l}\text { Financiamento da Empresa } \\
\text { Orientado por Política Pública }\end{array}$} \\
\hline & & $\begin{array}{c}\text { ICT } \\
\text { Outra Empresa }\end{array}$ & Compra de PD\&D & \\
\hline \multirow{2}{*}{ BNDES } & \multirow{2}{*}{ BNDES } & Empresa & Empréstimo & Financiamento da Empresa \\
\hline & & ICT & Transferência & Financiamento Público \\
\hline \multirow{3}{*}{ Petrobras (extra-ANP) } & \multirow{3}{*}{ Petrobras } & Própria Empresa & $\begin{array}{l}\text { Execução interna com } \\
\text { recursos internos }\end{array}$ & \multirow{3}{*}{$\begin{array}{l}\text { Financiamento de Empresa } \\
\text { Estatal }\end{array}$} \\
\hline & & ICT & \multirow{2}{*}{ Compra de PD\&D } & \\
\hline & & Outra Empresa & & \\
\hline LOA & MCTI & $\begin{array}{l}\text { Instituições Públicas } \\
\text { Federais }\end{array}$ & Transferência & Financiamento Público \\
\hline $\begin{array}{l}\text { Receita Tributária do } \\
\text { Estado de São Paulo }\end{array}$ & FAPESP & ICT & Transferência & Financiamento Público \\
\hline
\end{tabular}

Fonte: Elaboração Própria.

A segunda coluna descreve o órgão público responsável pela gestão dos projetos e pelo fornecimento da informação. Neste caso temos exclusivamente órgãos públicos estatais ou para-estatais. A terceira coluna apresenta a entidade responsável pela execução dos recursos de PD\&D. A quarta coluna mostra a natureza do fluxo de PD\&D segundo o Manual Frascati e a quinta coluna como as fontes de financiamento são contabilizados de acordo com este manual, sendo que, especificamente, para as empresas adicionamos o conceito de recurso orientado por políticas públicas.

Esse quadro nos permite perceber que, se bem a origem da informação dos dados seja de entes públicos, uma parcela substancial desses recursos pode ser considerada como financiamento de empresa. Por outro lado, o quadro esclarece como ocorrem os fluxos de investimentos públicos que são executados tanto por órgãos públicos, Instituições de Ciência e Tecnologia (ICT), como por empresas. Também revela que há recursos de origem empresarial, seja de empresa estatal ou privada, que são executados por ICT e outras empresas.

Após o levantamento dos dados e análise das informações disponíveis em cada base de dados, procedemos à consolidação desses dados. Assim, as estimativas apresentadas reúnem os dados das 
seguintes bases ${ }^{6}$ : FNDCT; FINEP; CNPq; ANP; Aneel; BNDES; FAPESP; Gastos Públicos em PD\&D de Energia como os referentes a Política Nuclear Brasileira e os investimentos de PD\&D da Petrobras.

\section{Estimativas dos investimentos de PD\&D em energia no Brasil}

Os números preliminares obtidos por esta pesquisa fornecem um bom quadro dos gastos públicos brasileiros com PD\&D em energia, incluindo combustíveis fósseis e energia nuclear. A tabela 1 inclui FNDCT, ANP, ANEEL, BNDES, FINEP (reembolsáveis), CNPq (extra FNDCT) e FAPESP, juntamente com os gastos da Petrobras e da Política Nuclear. Embora esse esforço de coleta de dados tenha sido abrangente, ainda é incompleto: os dados da ANP só estão completos para o ano de 2018. Também foi evitada a dupla contagem, como no caso dos dados da ANP/ANEEL e da Petrobras, e no caso dos dados da Política Nuclear e do FNDCT. Contudo, não foi possível desagregar dados entre entidades financiadoras e executoras, pois a informação não estava disponível na devida forma em algumas bases como Petrobras, Política Nuclear e FAPESP. De forma que este trabalho considera apenas as instituições financiadoras.

A Tabela 1 mostra a evolução dos dispêndios públicos ou publicamente orientados em PD\&D durante o quinquênio 2013-2018. O ano de 2014 representa o ápice desses investimentos, quando alcançaram um volume total acima de US\$ 1,8 bilhão. Observa-se que houve uma diminuição em valor constante desses investimentos de mais de $30 \%$ entre 2014 e 2017 em consequência do crise econômica e cortes profundos nos gastos federais, os quais caíram para um pouco mais de 1,2 bilhão neste último ano. Em 2018, em compensação, houve um aumento de $10 \%$ nesses gastos, com forte participação dos combustíveis fósseis, pelos dados completos da ANP que estão completos apenas para 2018 Estes, em particular os hidrocarbonetos, representam cerca de metade dos esforços de PD\&D de energia. As outras categorias importantes são transmissão de eletricidade e energia nuclear. Os biocombustíveis são a fonte de energia renovável mais importante. A participação das fontes renováveis no total de investimentos em PD\&D de energia caiu de 15,2\% em 2015 para 9,0\% em 2018.

A Gráfico 1 mostra a distribuição dos esforços públicos de PD\&D em energia por categoria de energia, aponta a queda dos investimentos em energia renovável junto com a energia nuclear nos últimos anos, juntamente com a recuperação dos investimentos em energia fóssil em 2018. Tal queda das renováveis não coincide com a evolução da $\mathrm{PD} \& \mathrm{D}$ em energias sustentáveis, cuja participação vinha melhorando até 2018 (Gráfico 2). Esta evolução favorável é explicada pelo fato de as categorias de Transmissão e Distribuição de Energia juntamente com as de Eficiência Energética terem mantido os seus valores, enquanto o Óleo e Gás sofreram uma redução acentuada após a queda dos preços internacionais em 2015. Porém, desde 2018 houve uma recuperação parcial de preços do petróleo, juntamente com o aumento da produção brasileira de petróleo.

Tabela 1: Gastos com PD\&D em energia no Brasil (US \$ 1000 em preços de 2018 e taxa de câmbio)

\begin{tabular}{|c|c|c|c|c|c|c|}
\hline & 2013 & 2014 & 2015 & 2016 & 2017 & 2018 \\
\hline 1.1. Indústria de Eficiência Energética & 593 & 497 & 457 & 183 & 121 & 80 \\
\hline 1.2. Edifícios de eficiência energética, residenciais & 24.687 & 29.404 & 20.479 & 1.536 & 1.396 & 5.045 \\
\hline 1.3. Transporte de eficiência energética & 6.132 & 11.973 & 13.235 & 56.969 & 53.030 & 53.001 \\
\hline 1.4. Outros Eficiência Energética & 14.243 & 13.406 & 12.578 & 15.990 & 20.444 & 20.914 \\
\hline 2.1. Óleo e gás & 945.520 & 960.801 & 726.373 & 590.163 & 576.194 & 734.674 \\
\hline 2.2. Carvão & 20.259 & 33.769 & 32.395 & 30.109 & 27.232 & 27.490 \\
\hline 2.3. Captura e armazenamento de $\mathrm{CO} 2$ & 1.191 & 891 & 477 & 625 & 1.750 & 5.020 \\
\hline 3.1. Energia solar & 52.802 & 45.475 & 13.991 & 24.148 & 29.622 & 32.836 \\
\hline 3.2. Energia eólica & 19.168 & 24.801 & 16.342 & 13.994 & 13.280 & 8.905 \\
\hline 3.3. Ocean Energy & 80 & 56 & 25 & 3 & 26 & 213 \\
\hline 3.4. Biocombustiveis & 110.922 & 173.288 & 145.278 & 105.634 & 87.489 & 65.504 \\
\hline 3,5. Energia geotérmica & 1.397 & 895 & 635 & 6 & 14 & 10 \\
\hline 3,6. Hidroel etricidade & 24.990 & 19.288 & 17.067 & 8.902 & 5.666 & 8.819 \\
\hline 3,7 . Outras fontes de energia renováveis & 16.056 & 18.182 & 16.803 & 17.993 & 17.205 & 16.312 \\
\hline 4.1. Ficão nuclear & 135.291 & 108.763 & 81.444 & 116.675 & 90.480 & 73.126 \\
\hline 4.2. Fusão nuclear & 505 & 1.511 & 1.224 & 850 & 538 & 378 \\
\hline 4,9. Fissão e fusão nuclear não alocada & 51 & 58 & 31 & 27 & 24 & 31 \\
\hline 5.1. Hidrogênio & 1.396 & 1.323 & 1.510 & 1.578 & 1.455 & 1.863 \\
\hline 5,2 Células de combustível & 1.120 & 701 & 806 & 561 & 44 & 295 \\
\hline 6.1. Geração de energia elétrica & 16.169 & 15.555 & 12.715 & 8.664 & 8.930 & 9.975 \\
\hline 6,2 Transmissão e distribuição de eletricidade & 249.660 & 327.660 & 332.242 & 301.416 & 295.022 & 298.473 \\
\hline 6.3 Armazenamento de energia (aplicações sem transporte) & 8.751 & 10.150 & 11.602 & 5.701 & 31.518 & 32.072 \\
\hline 7.1 Análise do sistema de energia & 28.420 & 27.065 & 30.344 & 27.506 & 24.037 & 15.126 \\
\hline Total & 1.679 .404 & 1.825 .512 & 1.488 .053 & 1.329 .235 & 1.285 .518 & 1.410 .160 \\
\hline
\end{tabular}

Fonte: elaboração própria.

\footnotetext{
${ }^{6}$ A caracterização das bases de dados utilizadas está disponível em CEPAL(2020) no link <https://www.cepal.org/ptbr/publicaciones/45908-overview-energy-innovation-investments-brazil-data-energy-big-push>.
} 


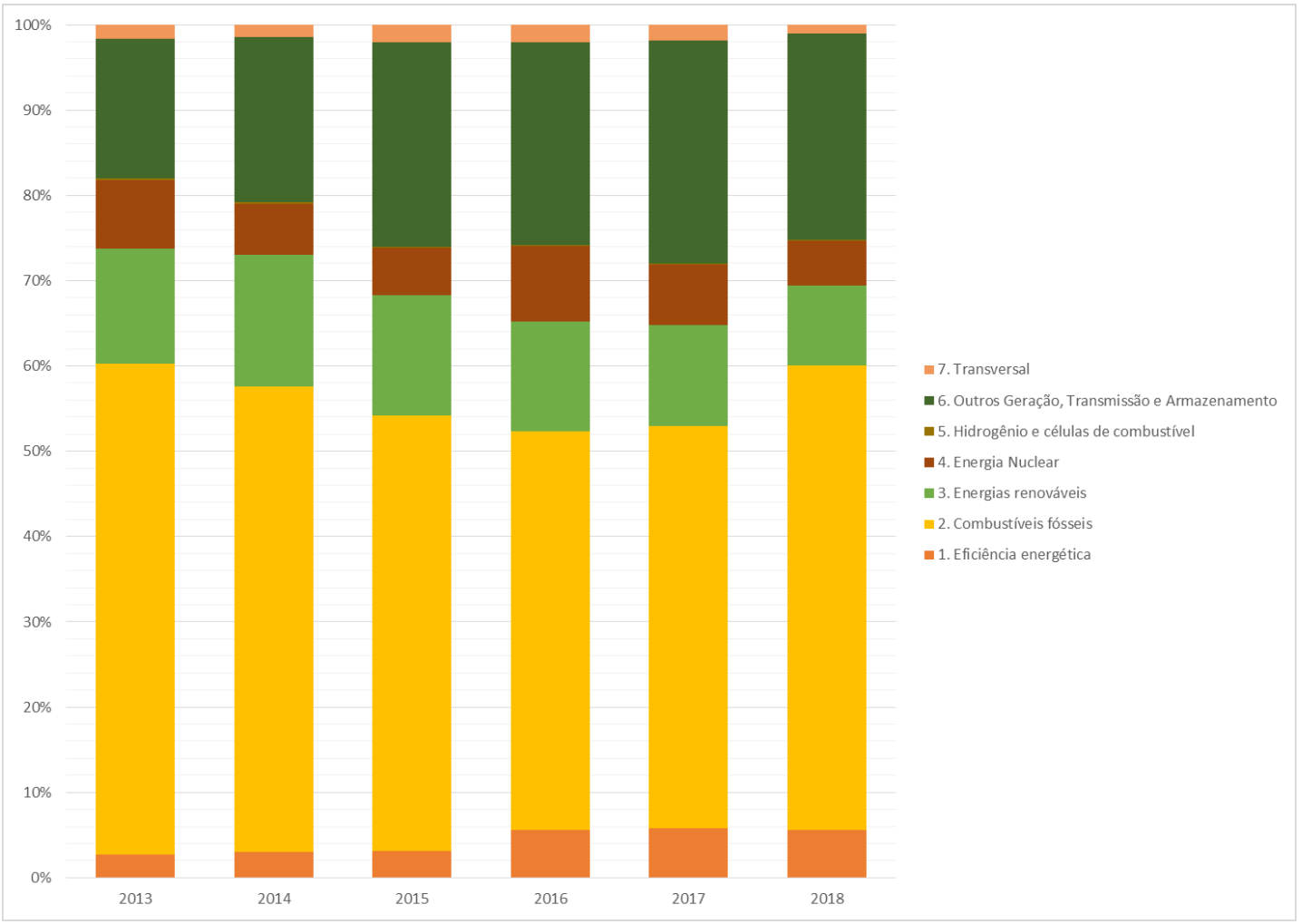

Gráfico 1: Distribuição dos esforços públicos de PD\&D por categorias de energia.

Fonte: elaboração própria.

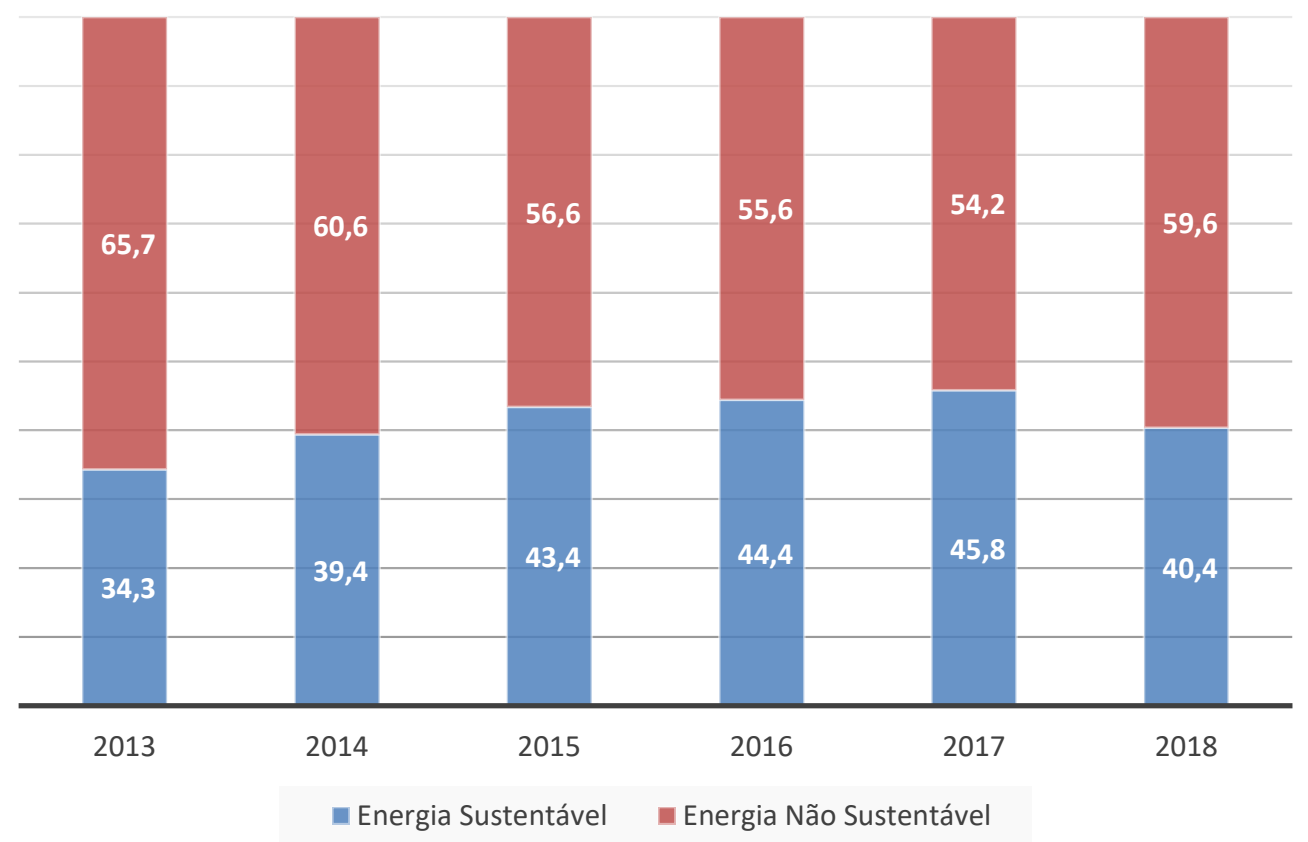

Gráfico 2: Participação dos esforços de energia sustentável na PD\&D brasileira.

Fonte: elaboração própria.

A Gráfico 3 mostra os dados sobre Tecnologias de Baixo Carbono de acordo com a definição da IEA (2011). Esta classificação inclui, adicionalmente, energias sustentáveis, energia nuclear e captura e armazenamento de $\mathrm{CO} 2$. Os números mostram um comportamento semelhante, já que essas tecnologias aumentaram sua participação até 2017, mas caíram devido à recuperação de combustíveis fósseis em 2018. 


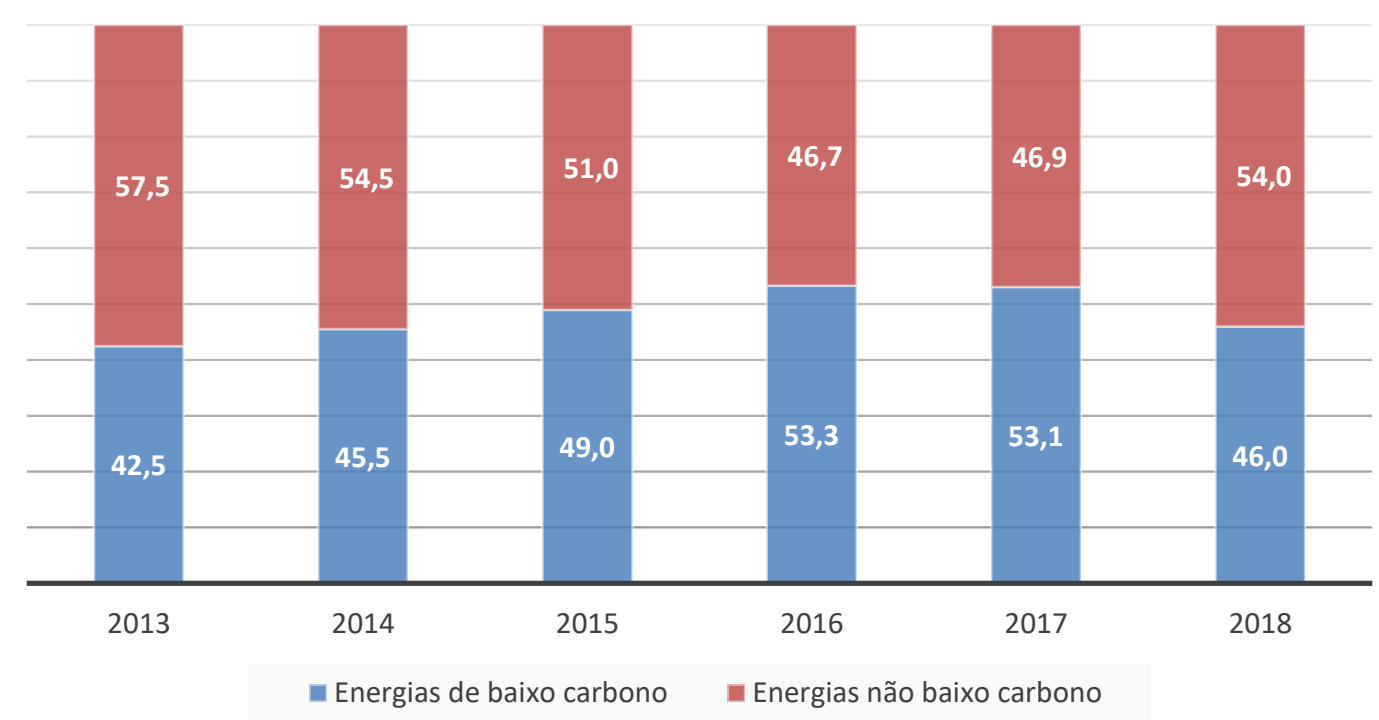

Gráfico 3: Participação dos esforços de energia de baixo carbono.

Fonte: elaboração própria.

Essa expressiva melhora dos investimentos em PD\&D em combustíveis fósseis em 2018 também pode ser observada na Gráfico 4. No entanto, outras gerações, transmissão e distribuição, junto com a eficiência energética mantiveram sua participação, enquanto as renováveis e a nuclear caíram nos últimos dois anos.
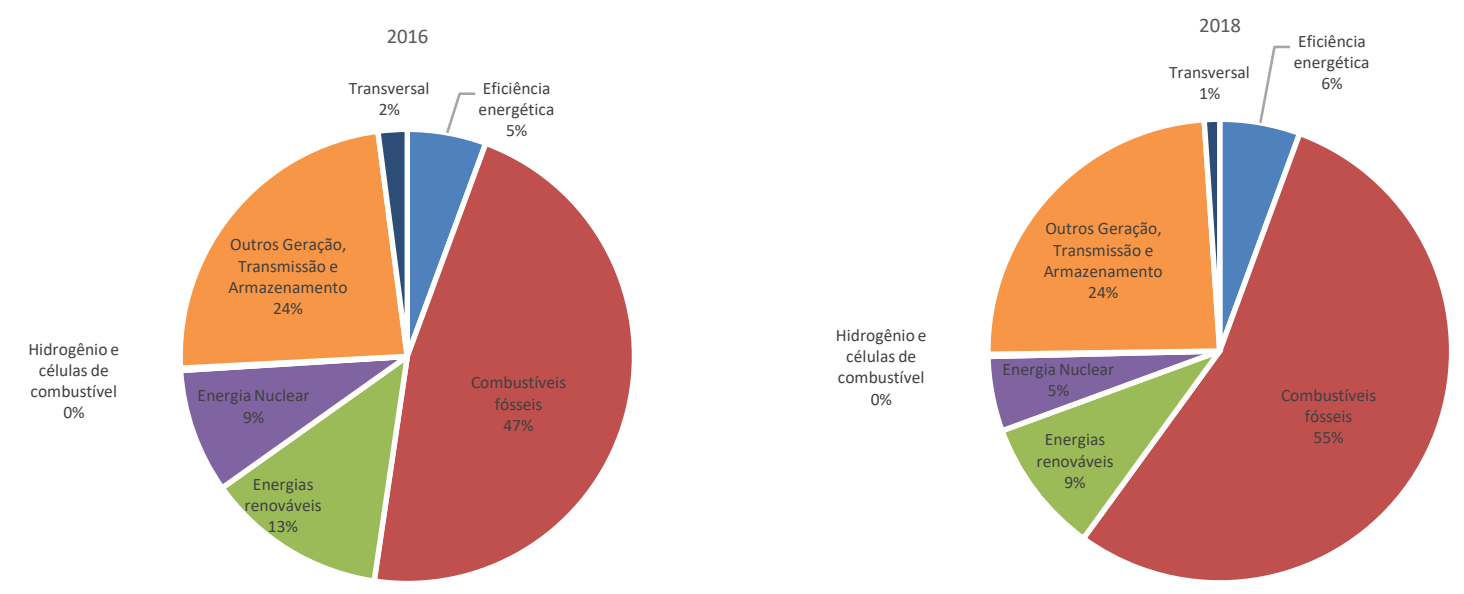

Gráfico 4: Distribuição dos esforços de P\&D de energia pública brasileira.

Fonte: elaboração própria.

Entre as Energias Sustentáveis verifica-se uma evolução semelhante, conforme se pode observar na Gráfico 5, com uma diminuição relativa das energias renováveis e categorias transversais de tecnologia, enquanto outras geração, transmissão e distribuição, juntamente com a eficiência energética melhoraram a sua participação. Vale ressaltar a baixíssima participação do hidrogênio e das células a combustível nos esforços públicos brasileiros de PD\&D. 

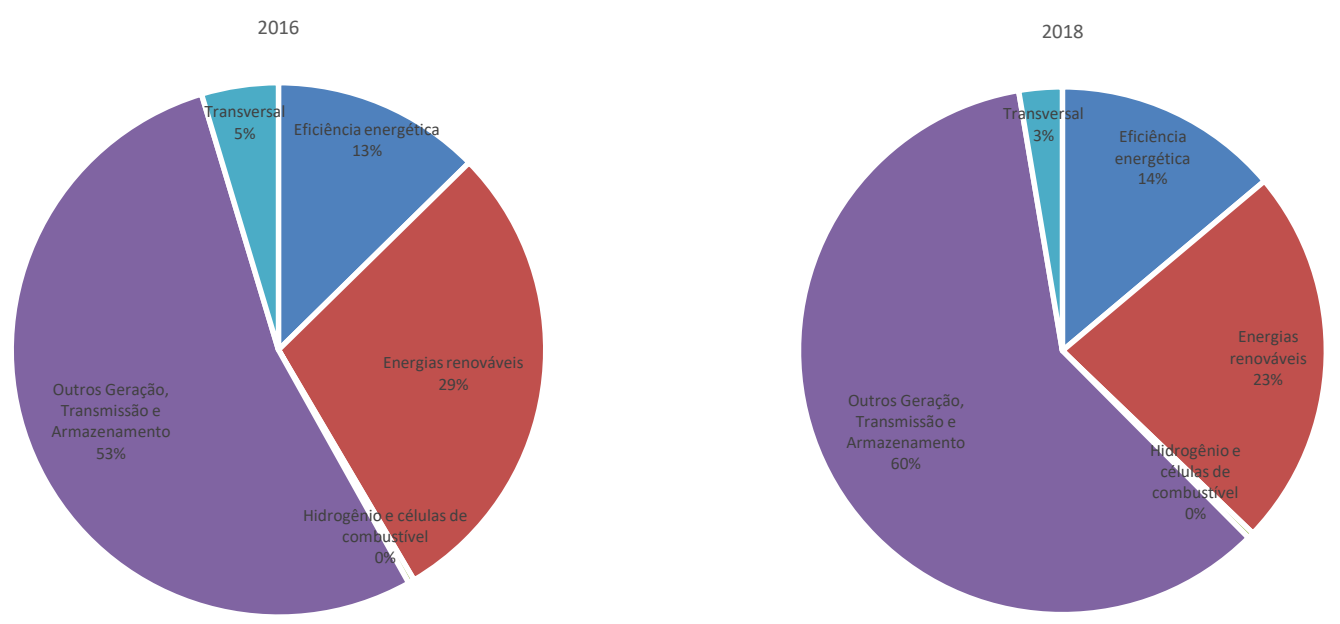

Gráfico 5: Distribuição de esforços de P\&D de energia sustentável.

Fonte: elaboração própria.

Em termos de esforços de P\&D em energia de baixo carbono, mostrado na Gráfico 6, é perceptível nos dois últimos anos a diminuição da participação da energia nuclear e das energias renováveis. No entanto, podemos observar o aumento da captura e armazenamento de $\mathrm{CO} 2$, o que pode ser explicado pelos esforços das petroleiras, principalmente Shell e Petrobras, no desenvolvimento de tecnologias para separar e reinjetar o $\mathrm{CO} 2$ associado à produção de petróleo e gás do Pré-sal.

2016

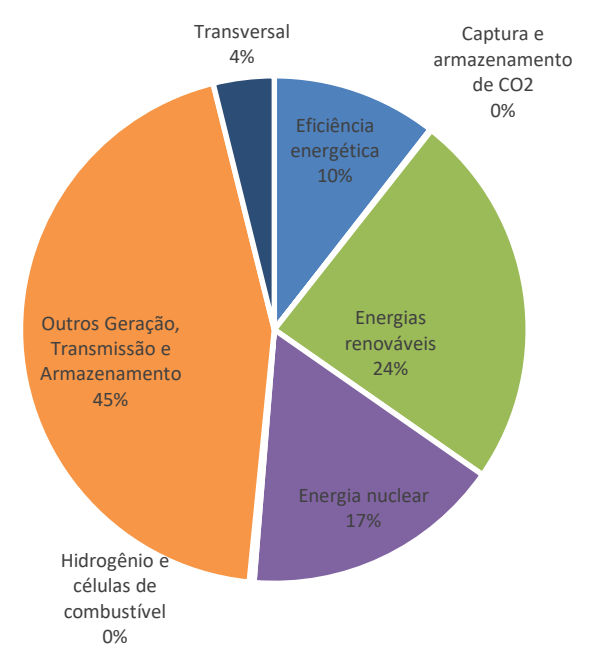

2018

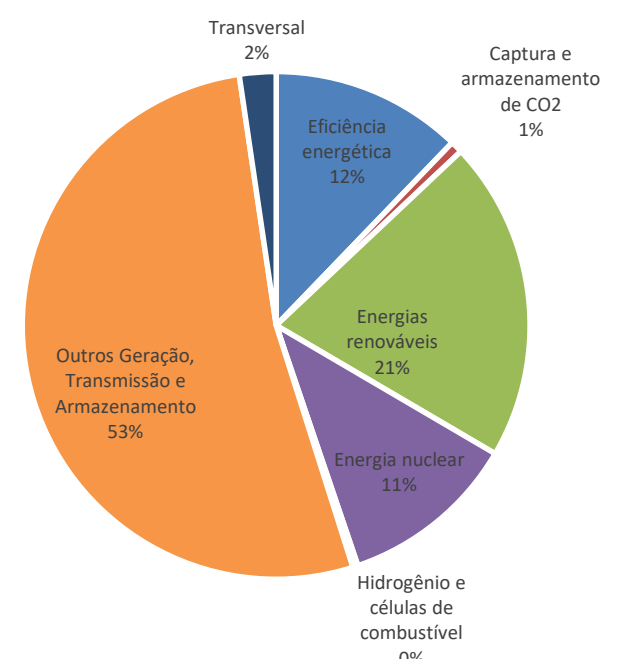

Gráfico 6: Distribuição de esforços de PD\&D de energia de baixo carbono.

Fonte: elaboração própria.

A Gráfico 7 mostra a evolução dos investimentos públicos brasileiros em PD\&D em energias renováveis entre 2013 e 2018. A principal fonte são os biocombustíveis, seguidos da energia solar, hidroelétrica e eólica. Os investimentos em PD\&D dessas fontes vêm caindo desde 2014 em valores constantes. 


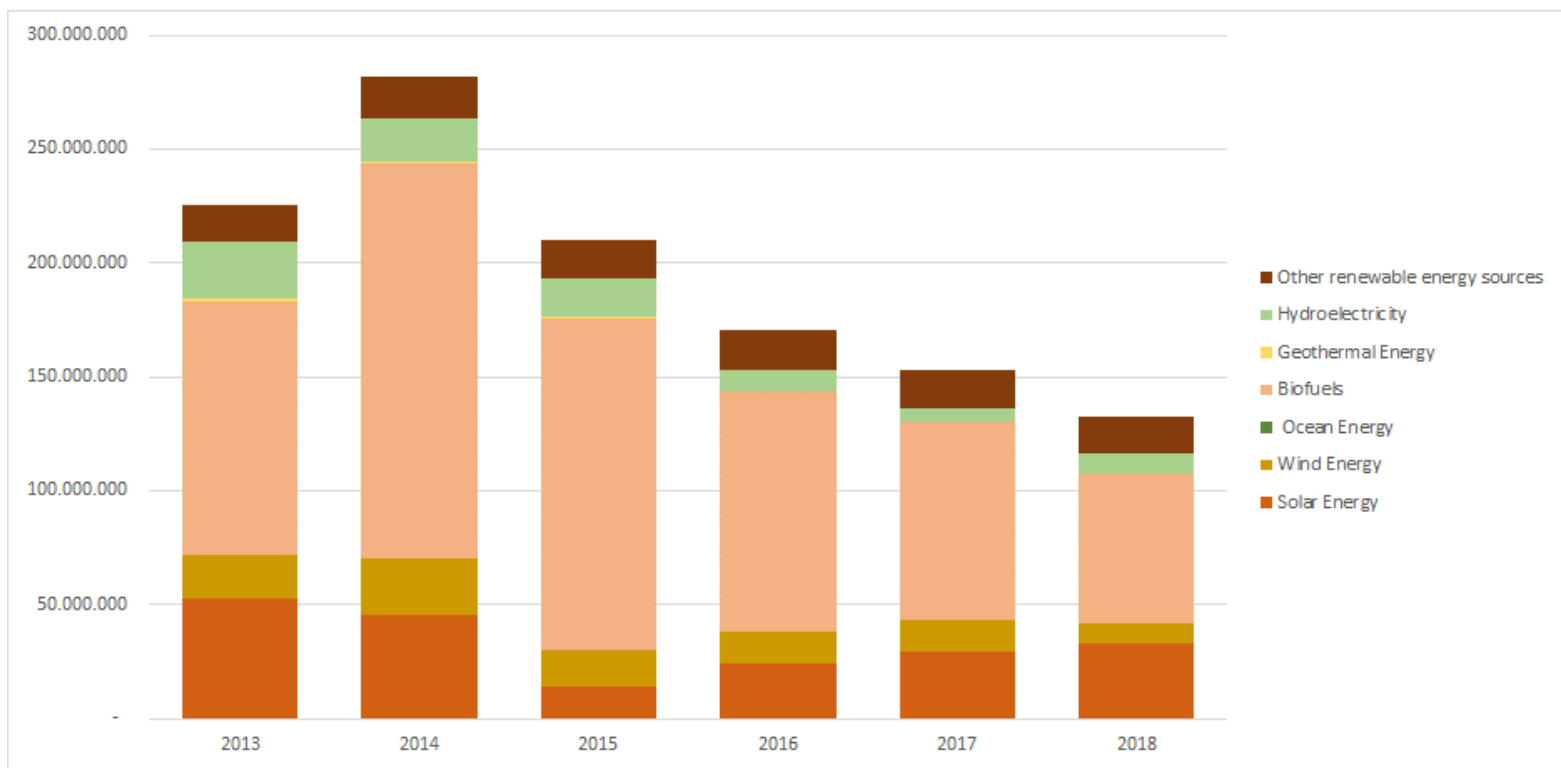

Gráfico 7: Investimentos em PD\&D em renováveis (US\$ em preços constantes e taxa de câmbio de 2018). Fonte: elaboração própria.

No entanto, a distribuição relativa dos investimentos públicos e publicamente orientados em PD\&D em energias renováveis mudou desde 2014, que foi o ano de pico, e 2018 (Gráfico 8). Os biocombustíveis perderam uma parte importante de seu avanço, enquanto a energia solar melhorou expressivamente sua posição.
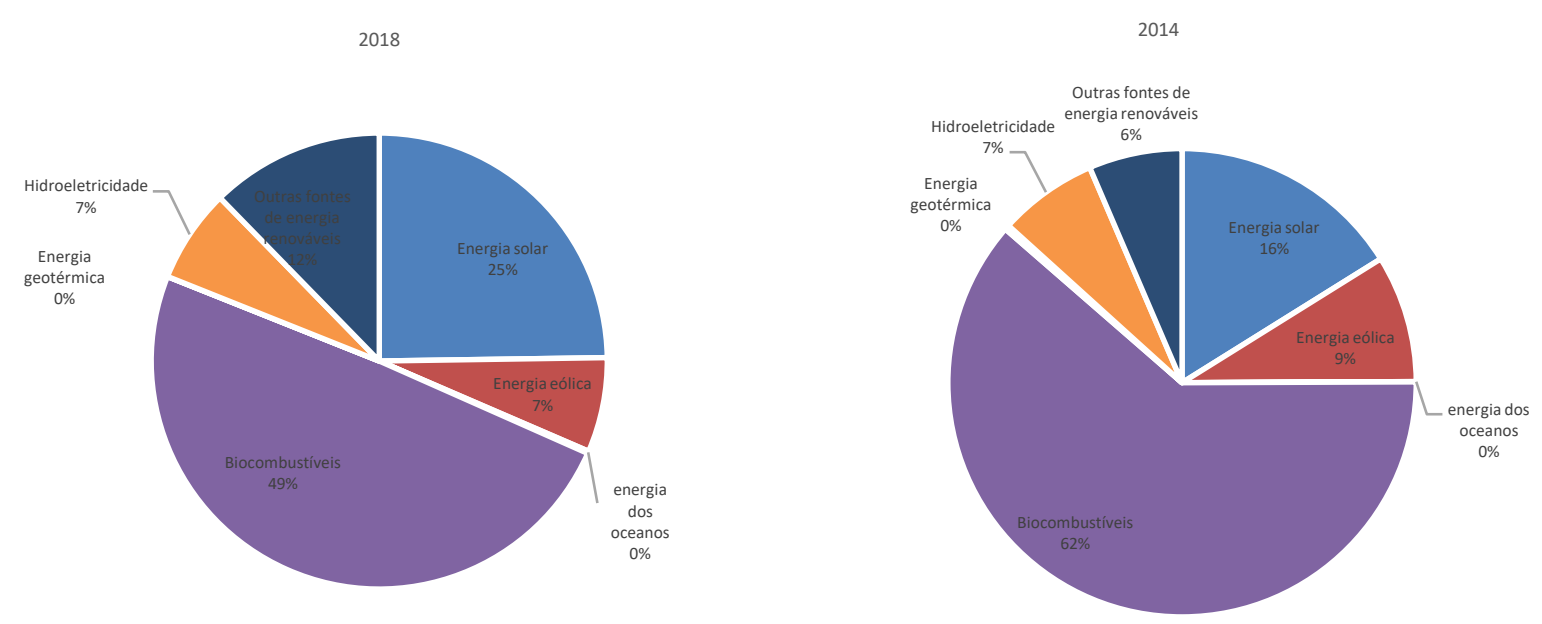

Gráfico 8: Distribuição dos esforços de PD\&D renováveis em 2014 e 2018.

Fonte: elaboração própria.

A Gráfico 9 aponta a participação dos Órgãos e Programas Federais nos Esforços de PD\&D em Energia Sustentável no Brasil. Revela a forte presença do BNDES e da ANEEL nesses esforços. No entanto, atores federais como FINEP e Petrobras reduziram expressivamente seus investimentos. A FINEP reduziu seus investimentos em eficiência energética e em energias renováveis, enquanto a Petrobras abandonou seus esforços em biocombustíveis. Essa involução também é perceptível no caso do FNDCT e do CNPq, cujos investimentos embora marginais são importantes na academia. O FNDCT é responsável pelos fundos setoriais, como o CTEnerg e o CTPetro, que foram importantes instrumentos de fomento à pesquisa básica e aplicada no setor de energia, mas têm assistido a uma queda regular desde 2013.

Os gastos da FAPESP com P\&D em energia sustentável durante este período foram mais constantes do que os gastos do CNPq e do FNDCT, demonstrando uma maior resiliência dos gastos com pesquisa acadêmica paulista à crise econômica do que a esfera federal. 


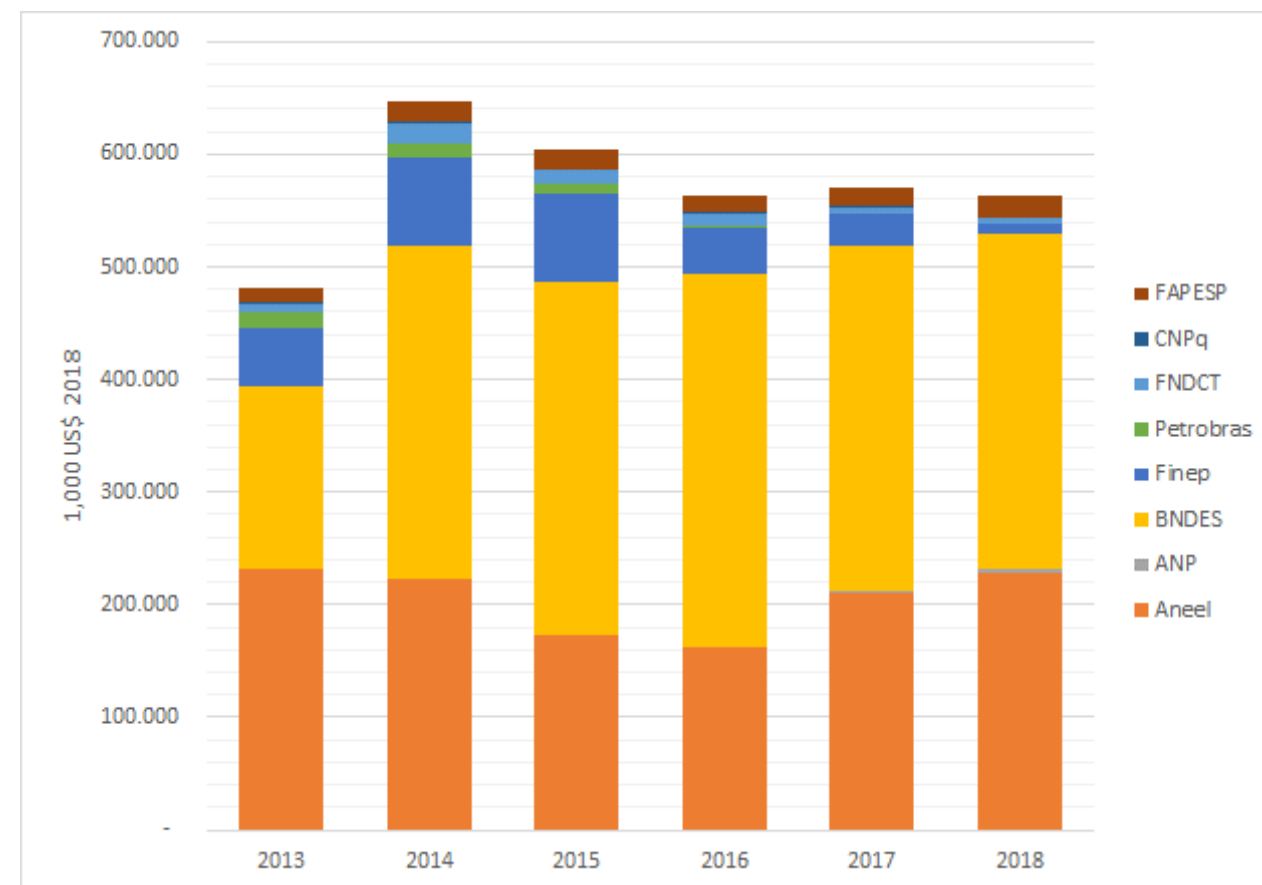

Gráfico 9: Participação dos Órgãos Federais e da FAPESP em Programas de Esforços de P\&D em Energia Sustentável

Fonte: elaboração própria.

\section{Considerações finais}

Esse trabalho representou um esforço importante para sistematizar e mensurar as informações sobre PD\&D em energia no Brasil. As primeiras estimativas fornecem subsídios para avaliação e adequação de políticas públicas na área de energia, ao mesmo tempo que trazem apontamentos sobre o potencial do país cumprir as metas acordas nas NDCs relativas ao Acordo de Paris. Além disso, permite a comparação internacional sobre os dados de PD\&D publicados pela IEA, ampliando as possibilidades de parcerias internacionais para desenvolvimento de determinadas áreas energéticas com vistas a promover o grande impulso energético no país, diversificando a matriz energética brasileira e tornando-a socioeconomicamente mais inclusiva.

Contudo, o levantamento possui algumas importantes limitações. A principal restrição constitui na cobertura incompleta dos financiamentos públicos federais e estaduais. Uma parcela importante do dispêndio federal em P\&D se faz por meio do Ministério de Educação e da Pós-graduação, estimada em $60 \%$ dos dispêndios em P\&D (MCTI, 2019b) ${ }^{7}$. Devido ao grande volume de informação e a consequente dificuldade de identificar o tipo de pesquisa realizada, não foi possível realizar a separação desses dados por tecnologia energética, mas em uma percepção mais abrangente deveriam ser contabilizados já que uma parcela dos programas de pós-graduação brasileiros atua na área de energia. Esse mesmo raciocínio vale para os dispêndios do Tesouro Estadual Paulista nas Universidades Estaduais. É bom lembrar que a IEA contabiliza os dispêndios em PD\&D em pesquisa básica e aplicada, onde deveriam ser contabilizados os investimentos em pós-graduação.

Tampouco foram objeto deste levantamento os dispêndios realizados pelas demais entidades do Governo Federal como o Ministério da Agricultura, onde são realizados vultuosos investimentos em P\&D, que equivaliam a 12\% dos investimentos federais em P\&D no Brasil em 2016 (MCTI, 2019b). Outra limitação diz respeito às empresas estatais. O levantamento realizado se restringe apenas à Petrobras, contudo o Grupo Eletrobrás continua sendo a principal geradora de energia elétrica do pais. Os investimentos realizados pela matriz, por meio do CEPEL, e pelas subsidiárias fora do contexto dos projetos da Aneel precisariam ser quantificados.

\footnotetext{
${ }^{7}$ Os dados do orçamento federal destinados à execução de PD\&D do Ministério da Educação estão inseridos no Programa 2080 - Educação de Qualidade para Todos. Destacamos as ações orçamentárias 0487 - Concessão de Bolsas de Ensino Superior, 20GK - Fomento as Ações de Graduação, Pós-Graduação, Pesquisa e Extensão e a Ação 20RK - Funcionamento de Instituições Federais de Ensino Superior. O cálculo da parcela destinada a PD\&D em energia dessas ações requereria o desenvolvimento de uma metodologia específica que permitiria a delimitação da parcela desses recursos destinada a cursos de pós-graduação relacionados com energia.
} 
Os dispêndios associados aos demais Estados da Federação, além do Estado de São Paulo, não foram estimados, tanto das Fundações Estaduais de Amparo à Pesquisa quanto do sistema de pósgraduação estadual. Também não temos uma estimativa dos investimentos em PD\&D das empresas que são realizados por fora do âmbito dos financiamentos públicos reembolsáveis e das obrigações de $\mathrm{P} \& \mathrm{D}$ da ANP e da Aneel. Importante destacar a incompletude dos dados da ANP, que certamente são expressivos, mas não estão refletidos neste estudo devido à incompletude da base de dados da agência que só possui dados completos para o ano de 2018. Ainda, a pesquisa de inovação do IBGE seria uma fonte importante de informações, mas que deveria ser complementada com perguntas específicas sobre as tecnologias energéticas a que se destinam os investimentos em PD\&D das empresas.

Apesar das limitações, as primeiras estimativas sobre os investimentos em PD\&D em energia no Brasil permitiram identificar a queda da participação dos investimentos em energias renováveis no total de investimentos em PD\&D, porém tal queda das renováveis não coincide com a evolução da PD\&D em energias sustentáveis, cuja participação vinha melhorando até 2018. Ressalta-se a baixíssima participação do hidrogênio e das células a combustível nos esforços públicos brasileiros de PD\&D. Já a evolução dos investimentos públicos brasileiros em PD\&D em energias renováveis entre 2013 e 2018, apontaram como principal fonte os biocombustíveis, seguidos da energia solar, hidroelétrica e eólica e, embora, os investimentos em PD\&D dessas fontes venham caindo desde 2014 em valores constantes, houve uma melhora expressiva dos investimentos em energia solar.

Com relação à participação dos Órgãos e Programas Federais nos Esforços de PD\&D em Energia Sustentável no Brasil, revelou-se a forte presença do BNDES e da ANEEL enquanto atores federais como FINEP e Petrobras reduziram expressivamente seus investimentos. Os gastos da FAPESP com PD\&D em energia sustentável mostraram-se mais constantes do que os gastos do CNPq e do FNDCT, demonstrando uma maior resiliência dos gastos com pesquisa acadêmica paulista à crise econômica do que a esfera federal.

\section{Investments in Research, Development and Demonstration in Energy in Brazil: measurement process and first results.}

Abstract: The article aims to present the process of measuring investments in research, development and demonstration (PD\&D) in energy in Brazil, as well as the first estimates of these amounts. These data are relevant for a better understanding of the final destination of resources to PD\&D, providing subsidies for the formulation and improvement of systematic public policies to boost the energy sector and promote the energy transition in the country. The measurement of investments in PD\&D, classifying them by energy category at a 2-digit level, according to the proposal of the International Energy Agency (IEA), allowed Brazil to integrate the agency's database and, from there, it will enable comparative analysis of these data with OECD countries. The scope of the information was restricted to secondary data sources from public agencies and the period of reference was from 2013 to 2018. The first estimates made it possible to identify the drop in the share of investments in renewable energy in the total investments in R\&D. The evolution of Brazilian public investments in PD\&D in renewable energies, between 2013 and 2018, points to biofuels and solar energy as the main sources. Regarding the participation of federal agencies and programs, there is a strong presence of BNDES and ANEEL, while FINEP and Petrobras significantly reduced their investments in energy R\&D in Brazil.

Keywords: renewable energy; federal expenditure; energy policy; energy planning;

\section{Referências bibliográficas}

ADAM, F. Measuring National Innovation Performance: The Innovation Union Scoreboard Revisited, 2014.

AGÊNCIA NACIONAL DE ENERGIA ELÉTRICA - ANEEL. Programa de Pesquisa e Desenvolvimento Tecnológico do Setor de Energia Elétrica. http://www.ANEEL.gov.br/programa-de-p-d. Acesso em 02/09/2019(a).

AGÊNCIA NACIONAL DE ENERGIA ELÉTRICA - ANEEL. Programa de Pesquisa e Desenvolvimento 
Tecnológico do Setor de Energia Elétrica. Transparência, Entidades Beneficiárias, publicado: 13/03/2018 08:33, última modificação: 03/05/2019. http://www.ANEEL.gov.br/programa-de-p-d. Acesso em 02/09/2019(b).

AGÊNCIA NACIONAL DE PETRÓLEO, GÁS E BIOCOMBUSTÍVEL - ANP. Projetos de PD\&I. Publicado em 04/06/2018, Atualizado em 25/06/2019. http://www.anp.gov.br/pesquisa-desenvolvimento-einovacao/investimentos-em-p-d-i/projetos-de-pd-i

BRASIL - REPÚBLICA FEDERATIVA DO BRASIL. Pretendida Contribuição Nacionalmente Determinada para Consecução do Objetivo da Convenção-Quadro das Nações Unidas sobre Mudança do Clima. MMA: Brasília. 2016. http://www.mma.gov.br/images/arquivo/80108/BRASIL\%20iNDC\%20portugues\%20FINAL.pdf

CENTRO DE GESTÃO E ESTUDOS ESTRATÉGICOS - CGEE. Necessidades e requisitos para a integração de ferramentas e métodos de análise de dados no CGEE. Análise de sistemas e ferramentas disponíveis e propostas para uma arquitetura integrada de dados e informações. Avaliação estratégica. Brasília: Centro de Gestão e Estudos Estratégicos, 2015.

EMPRESA DE PESQUISA ENERGÉTICA - EPE. Plano Decenal de Expansão de Energia 2027. Ministério de Minas e Energia. Empresa de Pesquisa Energética. Brasília: MME/EPE, 2018.

FUNDAÇÃO DE AMPARO A PESQUISA DO ESTADO DE SÃO PAULO - FAPESP. Indicadores FAPESP de Ciência, Tecnologia e Inovação. Boletim n04, Maio de 2014. http://www.fapesp.br/indicadores/boletim4.pdf

FINANCIADORA DE ESTUDOS E PROJETOS - FINEP. Composição do FNDCT. Disponível em <http://www.FINEP.gov.br/a-FINEP-externo/fndct/estrutura-orcamentaria/composicao-do-fndct>

Acessado em 30 de agosto. 2019.

FORAY, D.; LHUILLERY, S. Structural changes in industrial R\&D in Europe and the US: towards a new model?, in Science and Public Policy, 37(6), July, p. 401-412, 2010.

FREEMAN, C.; SOETE, L. Developing science, technology and innovation indicators: what we can learn from the past. UNU- MERIT Working Paper Series. The Netherlands: Maastricht, 2007.

FURTADO, A.T. (2015) Políticas de Inovação no Setor Elétrico Brasileiro. Edufes: Vitória.

HOLLANDA, S. Dispêndios em C\&T e P\&D. In VIOTTI, Eduardo Baumgratz; MACEDO, Mariano de Matos (Org.). Indicadores de Ciência, Tecnologia e Inovação no Brasil. Capitulo 2. Campinas: Editora da Unicamp, 2003.

IIZUKA, M.; HOLLANDERS, H. The Need to Customize Innovation Indicators in Developing Countries. UNUMERIT Working Paper Series. Maastricht University: The Netherlands, 2017.

INSTITUTO BRASILEIRO DE GEOGRAFIA E ESTATÍSTICA. Pesquisa de inovação. [Vários anos]. Disponível em: <http://www.pintec.ibge.gov.br/> Acesso em: 15 mar. 2016.

INTERNATIONAL ENERGY AGENCY. IEA Guide to Reporting Energy RD\&D Budget/Expenditures Statistics. OECD: France, 2011.

INTERNATIONAL ENERGY AGENCY. IEA, Questionnaire for in-depth Energy Policy Reviews 2015-16 Cycle, IEA/OECD, IEA/SLT(2015)4, Paris: 01-Jun-2015.

MINISTÉRIO DE CIENCIA, TECNOLOGIA E INOVAÇÕES - MCTI. Indicadores Nacionais de Ciência, Tecnologia Inovação. Recursos Aplicados. Governo Federal. Tabela 2.2.3 Brasil: Dispêndios do governo federal em ciência e tecnologia (C\&T), aplicados pelo Ministério da Ciência, Tecnologia e Inovação (MCTI), por unidade orçamentária e 2000-2016. https://www.MCTI.gov.br/MCTI/opencms/indicadores/detalhe/recursos aplicados/governo federal/2 2 3.html. Acesso em 02/09/2019(a).

MINISTÉRIO DE CIENCIA, TECNOLOGIA E INOVAÇÕES - MCTI. Indicadores Nacionais de Ciência, Tecnologia Inovação. Recursos Aplicados. Governo Federal. Tabela 2.2.2 Brasil: Dispêndios do governo federal em ciência e tecnologia (C\&T)(1) (2) por órgão, 20002016. < https://www.MCTI.gov.br/MCTI/opencms/indicadores/detalhe/recursos aplicados/governo feder al/2 2 2.html >. Acesso em 02/09/2019(b).

OBJETIVOS DO DESENVOLVIMENTO SUSTENTÁVEL - ODS. Disponível em http://www.itamaraty.gov.br/images/ed desenvsust/20160119-ODS.pdf Acessado em 22 julho 2019.

OECD , Frascati Manual 2015: Guidelines for Collecting and Reporting Data on Research and Experimental Development, The Measurement of Scientific, Technological and Innovation Activities, OECD Publishing, Paris, 2015. DOI: http://dx.doi.org/10.1787/9789264239012-en 
OECD. Frascati Manual. Proposed standard practice for surveys on research an experimental development. Paris: OECD Publishing, 2002.

PACHECO, C. A. O FNDCT e a Reforma do Financiamento de CT\&I. Slides presented to the Federal Senate Science and Technology Commission. Brasília, 12 June 2018. Available at: http://legis.senado.leg.br/sdleggetter/documento/download/ebf9627c-745f-4afc-924f-7ddfa0db17dc. Access in 16/12/2019.

PETROBRAS, Form 20 F. Petrobras, Relações com Investidores, Resultados e Comunicados, Relatórios Anuais, Vários Anos. https://www.investidorpetrobras.com.br/pt/resultados-e-comunicados/relatoriosanuais. Acesso em 02/09/2019.

SANTOS, G. R. (2015) Financiamento Público da Pesquisa em Energias Renováveis no Brasil: A Contribuição dos Fundos Setoriais de Inovação Tecnológica. Texto para Discussão 2047. IPEA: Rio e Janeiro.

SENADO FEDERAL, Portal do Orçamento, Siga Brasil Relatórios. <http://www8.senado.gov.br/BOE/BI/logon/start.do?ivsLogonToken=www8a.senado.gov.br\%3A6400\% 401122233JO3eU1387Jgl8X7bRnh87N5PRUbmn2zwo1122231Jv7pI1k8vwHtNMH6XfzyCe9E5M7R9sOw2 2. Acesso em 06/09/2019.

VIOTTI, Eduardo Baumgratz; MACEDO, Mariano de Matos (Org.). Indicadores de Ciência, Tecnologia e Inovação no Brasil. Campinas: Editora da Unicamp, 2003. 